\title{
TOWARD A CONVERGENT MODEL OF FLEXIBILITY IN ARCHITECTURE
}

\author{
Maryam GHARAVI ALKHANSARI ${ }^{*}$ \\ School of Architecture, College of Fine Arts, University of Tehran, Enghelab Avenue \\ 14174-66191, Tehran, Iran
}

Received 30 May 2017; accepted 19 April 2018

\begin{abstract}
With recent advances in technology, fundamental changes have occurred in architectural flexibility methods, a great deal of experience has been gained, and many strategies and tactics have been developed in this field. However, a convergence is lacking in these experiences, methods, and tactics, which raises a need for providing a convergent approach in this regard. In this paper, it is going to propose such a model of flexibility. To do this, it is first reviewed the general concepts of flexibility, and provide a short review of its history and its main executional tactics. It is then divided its main tactics into eight main groups of: 'open plan', 'pre-fabricated modules', 'similar spaces', 'extendable unit', 'attachment and detachment of adjacent units', 'common space between adjacent units', 'portable walls', and 'retractable furniture in a multifunctional space'. Analyzing these tactics, it is extracted the three fundamental principles of flexibility: 'soft connection', 'diversity and multiplicity of spaces', and 'multifunctional space'. Accordingly, this paper proposes a concise rule for flexibility as: 'soft connections between spaces' which implies to the three principles if some special attentions are paid. Although the rule seems to be simple, the paper argumentations show that paying attention to what it implies, can produce much more flexible spaces than what is created generally. At the same time, new creative ideas along supported by new emerging technologies can enrich these simple solutions extensively.
\end{abstract}

Keywords: architectural flexibility, flexibility history, flexibility tactics, flexibility principles, the soft connection, multifunctional space.

\section{Introduction}

Flexibility is nature's fundamental way of adapting to changing circumstances. Regarding the continual changing of human life and the occupant needs, flexibility has long been considered in architecture. In traditional buildings at different regions with different cultures, flexibility has occurred in similar ways. Encountering recent advances in technology, it has been produced various methods about flexibility. While the rate of change in contemporary human life is accelerating, flexibility is proposed as a vital necessity in recent architecture. On the other hand, the multiplicity of approaches to this subject has made a kind of confusion about it. Sometimes it seems that reaching flexibility in architecture is an ambiguous and complicated process. In Lynch's words, the plurality of intervening factors relating flexibility (such as individual characteristics, social-cultural values, predictable and unpredictable future) cause this notion to be unclear. He says that 'however frequently flexibility is invoked, its meaning remains unclear... No one knows quite how to attain it' (Lynch, 1984, p. 68). Grütter believes that flexibility should be reached in an organized process otherwise it may lead to disorder (Grütter, 1987). James Stirling declares that he is 'sick and tired of the boring, meaningless, non-committed, faceless flexibility and open-endedness of the present architecture' (Stilling in Schneider \& Till, 2007). In Schneider and Till's words, 'if flexibility in housing is to achieve its full potential, it has to mean more than endless change without any fixed determinants' (Schneider \& Till, 2007, p. 158). They believe that 'the desire for flexibility often led to programmatically neutral, characterless buildings. Flexibility became synonymous with blandness' (Schneider \& Till, 2005). This paper believes that the proposed problems have come up partially due to the ambiguity of the subject as well as the multiplicity of applied methods. This multiplicity raises a need for providing a convergent approach in this regard. The main objective of this paper is moving toward opening a new

*Corresponding author. E-mail: mgharavi@ut.ac.ir 
analytical viewpoint about flexibility in architecture and proposing a convergent model in this regard.

Accordingly, at the first step, this paper aims to organize the variety of flexibility tactics in order to provide a context for a theoretical analysis in this area. Presenting a general introduction to related experiences, at the next step, the paper discusses the different aspects of flexibility provided by the experiences and presenting some categories. Analyzing the categories leads to extract three fundamental principles. This paper believes that these three principles cover different features of architectural flexibility and can be a suitable base for proposing a comprehensive model in this relation.

The main approach of the research is based on qualitative analysis. It tries to take advantage of interpretiveanalytic methods to study basic historical and contemporary discussions about flexibility along with analyzing 33 case studies (presented in Table 1a, 1b, and 1c) in order to extract new categorizations. The case studies are chosen from contemporary and also traditional buildings. The inductive base of qualitative discussions of the research will be strengthened by logical argumentation. The main tactics of gathering information are evidential and librarybased studies.

\section{Research background}

Some of the main published researches about flexibility have been categorized here:

- The researches about 'Portable Architecture' has been done by Robert Kronenburg in the University of Liverpool which has been led to several publications in this area. The book 'Houses in Motion' (published in 2002), reviews the history of portable structures and studies the characteristics of portable, transportable, demountable and temporary architecture. 'Flexible' (published in 2007), investigates the flexible architecture buildings that respond to evolving situations in their form, operation, or location. The samples introduced contains subjects such as architecture, interior design, product design, and furniture design. In 'Portable Architecture' (published in 2008) he situates portable architecture as a vital and expanding characteristic in contemporary life and introduces some contemporary mobile structures in different functional groups. 'Living in Motion' (published in 2013) introduces modern and technological approaches toward flexible buildings.

This branch of studies emphasizes mostly on movable and portable characteristics of a flexible architecture. Thereupon, while considering the conceptual subjects, the discusses are mostly dependent on the executive technics and structural evolutions. In this regard, new technologies have been made fundamental changes and the researchers explore the new horizons in this regard.

- The researches about 'Open Building System' which contain 'System Buildings' and 'Open-Ended design' research titles and have been proposed and started mainly by N. J. Habraken as the director of SAR research group in Netherland. In the books such as 'Variations: The Systematic Design of Supports' (published in 1974) and 'Supports: An Alternative to Mass Housing' (published in 1999) published by Habraken and his research group, it is explained the support/infill approach to housing, one of the effective movement of the housing now implemented worldwide and provided a systematic process toward flexibility. In 'Residential Open Building' (published in 2000) - the result of a CIB Task Group 'Open Building Implementation' - it is presented a review of the open building, fundamental principles and recent developments in this area.

This group of studies concentrates on the flexibility tactics that can be applied especially in mass housing and prefabricated design process. The researchers introduce methods in which there can provide a variety of design ideas in an invariant structure.

- The researches about 'Flexible Housing' by Tatjana Schneider and Jeremy Till in the University of Sheffield which lead to the publication of 'Flexible Housing' (published in 2007). In this research, it is introduced several international examples of flexible houses and it describes the structural, social and economic analysis in this regard. It is also introduced some tactics and discusses their effect on the flexibility in housing.

As the research titles show, flexibility can be studied from different aspects. While the first group of studies explores the portable and transportable ideas, the second group concentrates on the variety of housing design alternatives on an invariant structural system and the third group investigates flexibility approaches in housing, this research provides a more general viewpoint, not dependent to a specific architectural functional or technological tendency. It tries to present a more comprehensive view of flexibility tactics, covering historical roots and evolutions along with contemporary multiple approaches. Accordingly, it will extract flexibility conceptual roots and principles presented in the final model and the presented concise rule as the main result. This research believes that such identified principles can clear much of the proposed ambiguities about the flexibility that has been interpreted as open-endedness (Stirlling in Schneider \& Till, 2007), blandness (Schneider \& Till, 2005), unclearness (Lynch, 1984, p. 68) or disorderliness (Grütter, 1987).

\section{Flexibility: meaning and domain}

Flexibility in architecture is necessary because of the continual change in the human life and also the human inward desire for variety and innovation in his living spaces. The human life changes as the external force and the human inherent will for variety as the internal force, are the two main sources providing motivation for flexibility. It can be said that flexibility is an approach that responds to the external and internal need to change, variety and evolution. 
Flexibility is an ability to respond to change (Kronenburg, 2007; Schneider \& Till, 2007). Some of the architectural spaces have the multi-functional abilities and can accommodate a range of activities, without physical changes or reorganization in a specific period or over time. Some of the spaces have the ability to change in order to respond to different needs and activities. Environmental designers use the terms adaptability and flexibility to define these two approaches (Einifar, 2003, pp. 66-67). Bentley proposes the term robustness to describe the ability of places that can be used for many different purposes and can offer their users more choices (Bentley, Alcock, Murrain, McGlynn, \& Smith, 1985, p. 10, p. 56). In architecture and environmental design, it can be described as the ability to change and reorganize the built environment to adapt new requirements (Einifar, 2003, p. 66). The considered concept of flexibility in this paper is a general approach that refers to both physical and functional ability to change. ${ }^{1}$

\section{Flexibility: a historical review}

It is used special tactics in Traditional buildings particularly residential type in order to respond to functional changes. In most cases, because of traditional structural systems, making changes in design organization was not easy and feasible. Accordingly, flexibility was achieved through creative tactics within structural limitations. Traditional spaces have special abilities to be multifunctional and to be merged so providing larger space or divided into small spaces. The hierarchy of the spaces provides different scales such as minor, middle and major spaces that can be suitable for a diversity of uses and changes. It is also provided light portable components (such as portable doors or windows) in non-bearing parts of the walls to reach the maximum range of flexibility (Einifar, 2003, p. 66). Samples of these architectures can be studied in classical European houses or traditional Persian house. In other traditional buildings using light materials and structure such as Japanese traditional houses and American immigrants' huts of the $19^{\text {th }}$ century $^{2}$, the flexibility has been provided through multi-functional spaces and portable walls. Using such methods may also be seen in some other historical buildings. For example, the Greek amphitheaters that have been continued in the Roman era have special multipurpose spaces with masonry structures. These spaces have changing equipment such as light portable roofs that respond to the changing requirements of the scene. Some of these technics continue in Middle Ages era (Kronenburg, 2002, pp. 41-42).

\footnotetext{
1 It may be defined some other types of flexibility in architecture such as climatic or structural flexibility. The ideas considered in this paper is mostly about functional aspects.

2 There are some samples represented in Table 2.
}

The industrial revolution and technical progress in the late 19 century leads to the production of a new type of free spaces. The Dom-ino house idea by Le Corbosier (1914) has provided new abilities for open plan design, what is called as plan libre. At the same time, Frank Lloyd Wright suggested the open plan design inspired by Japanese houses and American immigrants' huts (Gardiner, 2002). Walter Gropius describes the modern open plan as a flexible shell that responds to the continual changes of the family needs during their life (Capon, 1999). Many other architects also paid attention to open plan ideas. For example, Theo Van Doesburg believes that new architecture is an open architecture (Grütter, 1987). Office buildings were among modern designs along with housing designs that use the idea of the open plan. Open office plans usually contain a central core including necessary services and a free zone around. The non-bearing walls in the free zone provide a flexible division of the spaces.

In the post-Modern era, modern strict functionalism was condemned and it is paid attention to the variety and plurality of functions. Robert Venturi has emphasized on multi-functional architectural spaces in his book, Complexity and Contradiction in Architecture (1966). Archigram and Metabolists paid attention to new ideas about futuristic flexible structures. At the same time, the Megastructure ideas proposed the permanent structure with changeable prefabricated modules that can move, change or adapt according to new circumstances (Capon, 1999, pp. 167-168). Along with new evolutions, criticism towards modern architecture intensified. Theorist architects such as Christopher Alexander criticized the human life divisions into specialized zones as what is done in the Modern era. He believed that such ideas are the origin of non-coherent and spiritless built environments. Charles Jencks introduces plurality and change as one of the four key characteristics of contemporary ideal architecture (Jencks, 1987).

\section{Flexibility: tactics and methods}

In the following part, the diversity of methods proposed about flexibility are categorized in eight main groups as the main flexible design tactics. These categories are derived by studying several flexible examples. A selection of 33 samples is presented in Table 1a, $1 \mathrm{~b}$ and 1c. The hierarchy of the tactics presented here is according to more systematic approaches moving to more partial methods.

\subsection{Tactic 1: open plan}

Contemporary progress in building technologies led to the freedom of the walls as the non-bearing elements and forming what is called the 'open plan'. The result of this system is the minimization the structural elements as the permanent parts of the building, making free other parts as the changeable elements. It can be suggested as a flexible design that responds to the variety of occupant demands according to different circumstances. The idea 
proposed by Le Corbusier as Domino was a turning point in this area (Samples 1,2,3). The flexibility provided by the large spans of Hi-tech architecture can be a special interpretation of the open plan. Other approaches such as open building system are an extended inspiration in this area (Samples 4, 5, 6). In open building system, it is considered an unfinished plan that has the potential of embedding several design alternatives. It is usually used modular prefabricated dividing walls for easy future changes in plan. There are also particular methods that provide possible movements of service elements such as kitchen or bathrooms. ${ }^{3}$ These potentials increase the possibility of changes in plan and design.

\subsection{Tactic 2: prefabricated modules}

The industrial building production and prefabrication industry have inspired some of the flexible approaches. The usage of construction technology for producing building components in a factory and attaching them in place of building site provides an easy, rapid and economic process of not only initial building but also future changes in the building. The buildings proposed by Archigram or Metabolists are based on the changing composition of prefabricated capsules that are assembled on a defined structure (Samples 7, 8). It is considered in some of the methods, flexible connections between capsules that let them be attached or detached along with new necessities. Another application of prefabricated industrial productions was used in portable architecture first proposed by Buckminster Fuller in Dymaxion house (Sample 12). In this house, the service elements were located in the central column and the furniture was designed to be portable and foldable. The whole unit was also portable (Marks, 1960, p. 130-131). Several ideas for portable architecture are proposed and produced afterward (Samples $9,10,11,13)$.

\subsection{Tactic 3: similar spaces}

In this tactic which is usually used in residential units, the design is composed of some similar rooms with nearly similar distribution and access. This allows the user to choose and embed his/her arbitrary composition of private and communal spaces (Samples 14, 15, 16).

\subsection{Tactic 4: extendable unit}

In this tactic, the flexibility is pursued through extendibility. The expandability of the design may be considered in a defined zone or it may occur in a free area. The defined zone may provide horizontal extension, when anticipated in the adjacent yard or may provide vertical extension when anticipated as the new floors that can be added (Samples 18, 19). In Expandable House designed by James Stirling and James Gowan, the house can grow according to the growth stages of a family unit both horizontally and vertically (Sample 17). So it is considered defined stages of a family transformations and the architecture can extend accordingly (Crinson, 2012).

In the other approach, extendability in a free area, it is anticipated some basic principles for the extension, but the dimensions and stages can occur more freely (Sample 21). The design for the Museum of Unlimited Growth by Le Corbusier, was composed in a spiral form that can be developed around the main core (Sample 20).

\subsection{Tactic 5: attachment or detachment of adjacent units}

Another idea proposed by some architects in order to increase flexibility is the ability to merge or split adjacent apartment units. It is usually used in residential apartments. This potential is usually provided through a nonbearing wall between the units that can easily be removed or located. Both plan alternatives, with or without the intermediate wall, anticipated providing suitable residential spaces (Samples 22, 23).

\subsection{Tactic 6: common space between adjacent units}

Considering a common space between adjacent units that can attach to any one of the units is another tactic used by some architects especially in residential apartments. The attachment or detachment can be decided according to the agreement between the adjacent users (Samples 24, 25).

\subsection{Tactic 7: portable walls}

In this tactic, it is located portable walls between spaces that provide the possibility of merging or splitting adjacent spaces. One of the first contemporary usages of this tactic was Mies van der Rohe design in residential units in Weissenhof neighborhood in Stuttgart (1927). In this design, the wooden non-bearing walls have bolt attachment to the ceiling and floor and so can easily be removed or inserted again, allowing the residents change the spaces compositions according to their needs (Grütter, 1987) (Other examples can be seen in Samples 26, 27).

\subsection{Tactic 8: retractable furniture in a multifunctional space}

In this tactic, the retractable furniture increases the diversity of the possible functions in the space (Samples $32,33)$. It is especially useful in the design of minimal apartments, where the multifunctional space is vital. In traditional buildings, particularly in eastern samples like Persian or Japanese houses (Sample 28, 30), the main life activities occur on the ground and the low number of the furniture are light and portable. Such characteristics of furniture allow the spaces to be used for many purposes.

The selected samples relating to eight introduced tactics are presented in Table $1 \mathrm{a}, 1 \mathrm{~b}$ and $1 \mathrm{c}$.

3 cf. (Kendell, 2000) 
Table 1a. Flexibility tactics

\begin{tabular}{|c|c|c|c|c|}
\hline \multicolumn{2}{|c|}{ Tactics } & \multicolumn{3}{|c|}{ Samples } \\
\hline $\begin{array}{l}\frac{\pi}{2} \\
\frac{\pi}{0}\end{array}$ & 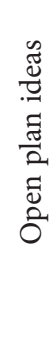 & 1 - Dom-ino House, 1914 & $\begin{array}{l}\text { 2- Columbus House, Berlin, } 1931 \\
\text { Architect: Erich Mendelson }\end{array}$ & 3- Fesstgasse, Austria, 1979 \\
\hline تِّ & 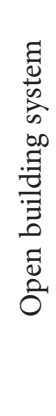 & $\begin{array}{l}\text { - Sample of SAR residential } \\
\text { complex } \\
\text { Architect: N. J. Habracken }\end{array}$ & $\begin{array}{l}\text { 5- Next 21, Japan, 1993 } \\
\text { Architects: Osaka Gas, SHU-Ko-SHA } \\
\text { arch. and urban design studio }\end{array}$ & 6 - Flexsus House 22, Japan, 2000 \\
\hline & 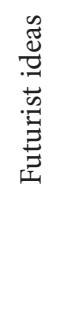 & $\begin{array}{l}\text { Archite Wolfgang Doerin } \\
\text { - Mega structures ideas } \\
\text { Archite }\end{array}$ & $\begin{array}{l}8 \text { - Yamanashi Broadcasting and } \\
\text { Press Centre, Japan } \\
\text { Architect: Kenzo Tange }\end{array}$ & \\
\hline 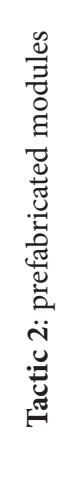 & 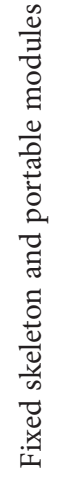 & $\begin{array}{c}\text { 9 - Les Marelles, France, } 1975 \\
\text { Architects: Bernard Kohn, Georges } \\
\text { Maurios }\end{array}$ & $\begin{array}{c}\text { 10 - Central Beheer Office Building, } \\
\text { Netherland, 1987 } \\
\text { Architect: Herman Hertzberger }\end{array}$ & 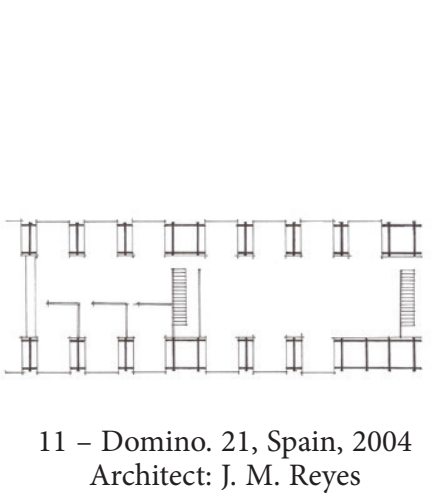 \\
\hline & 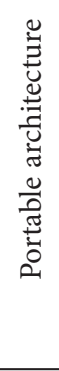 & 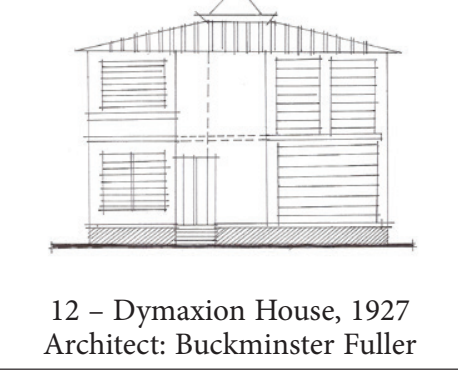 & $\begin{array}{l}13 \text { - Designing portable } \\
\text { residential unit } \\
\text { Architect: Ionel Schein }\end{array}$ & \\
\hline
\end{tabular}


Table 1b. Flexibility tactics

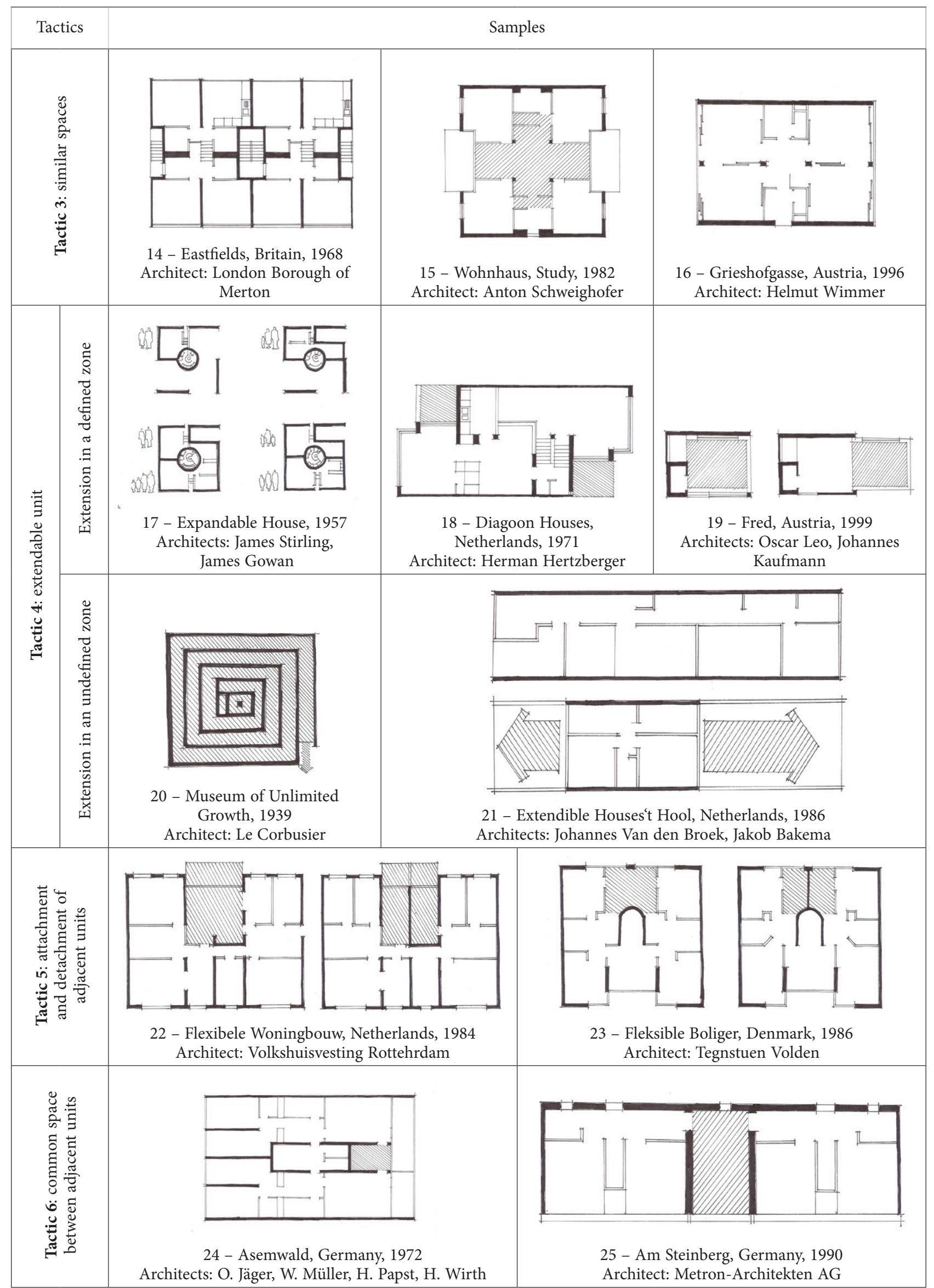


Table 1c. Flexibility tactics

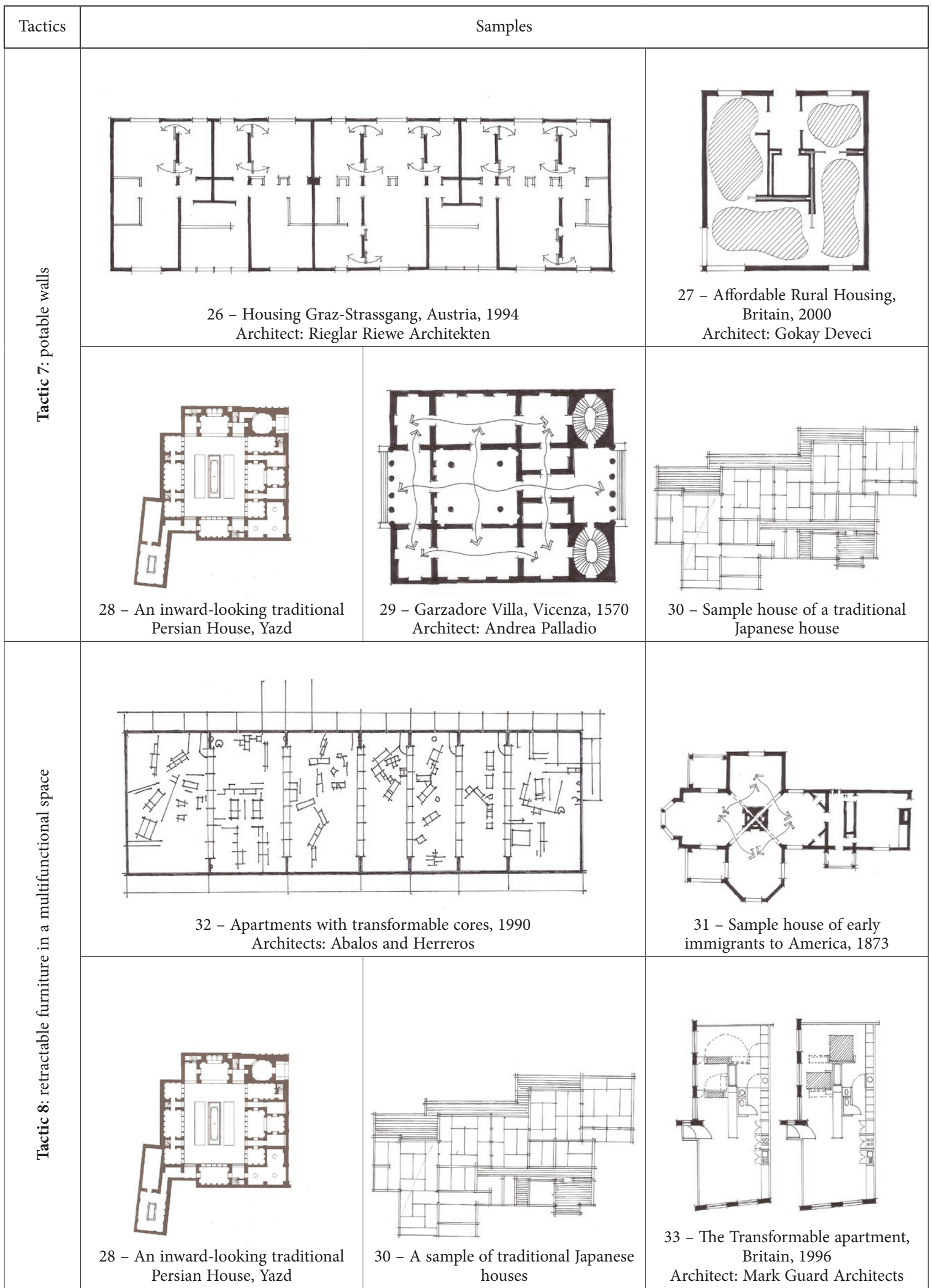




\section{Principles of flexibility}

Analyzing the tactics introduced, this part is going to extract some general features that can be introduced as basic principles of flexibility.

\subsection{Principle 1: soft connection}

In most of the tactics, flexibility is dependent on the soft connection. What is called soft connection in this paper, means a particular connection that has the ability to adjust the relationship between its adjacent spaces. The soft connection can allow the extension of one space into the adjacent zones, when it seems that more extent space is needed and vice versa. Thereupon, the space zones can be extended or retracted according to necessities. Gao believes that a quiet spatial ambiance can be created by closing and connecting various parts of the home space (Gao, 2012, p. 28). The combination of the home space can integrate the advantages and characteristics of different spaces as well as cover the shortages (Gao, 2012, p. 64).

The soft connections can be presented as two particular types:

- The first type is in the form of a portable wall or an adjustable threshold that can be opened or closed. In this situation, the expansion or retraction of a space can occur directly in the adjacent area. This soft connection may also be portable so it has the ability to be moved or removed. Accordingly, considering the location and number of soft connections of a space, the soft edges of the space can be opened, closed, moved or removed. It is important to note that the quality of softness of the connection and its location is dependent on the space properties and it can affect the place quality.

- The second type of the soft connection can be in the form of an intermediate space as a joint that provides soft connections (type 1) while adjoining its adjacent spaces. In this condition, the expansion of the space can occur in two stage. In the first one, the space can expand into the joint space. In the next stage, if more extension is needed, the space may penetrate into the second space adjacent to the joint. This process is shown in Table 2.

This principle can be investigated in several tactics of flexibility i.e. tactic 7 , portable walls. In other tactics, this property can also be detected. For example, in tactic 2, prefabricated modules, soft connections as light and changeable walls usually can adjust the modules connec-

Table 2. Different types of the soft connection

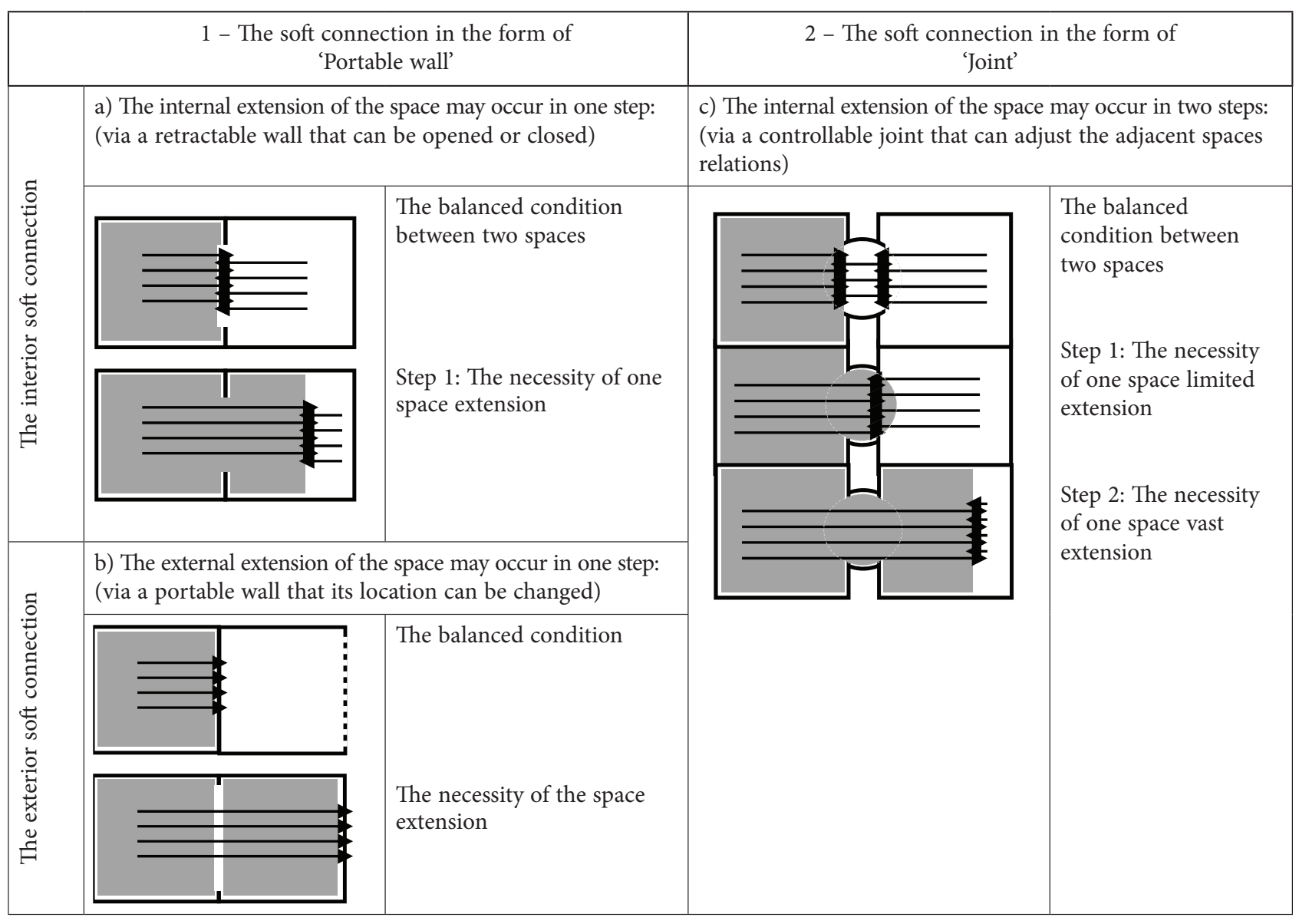


tions ${ }^{4}$. In tactic 5, attachment and detachment of adjacent units, light walls as soft connections can be followed in the location of adjacent units' connections ${ }^{5}$. In tactic 6, common space between adjacent units, it is considered a common space for future development of the units. This common space should have the soft connection in order to be adjusted and can be attached or detached to its adjacent spaces. In tactic 1 , the open plan, the soft connection helps to regulate the external or internal walls. In sample 3 (tactic 1), the soft connection helps the external walls to be moved freely. In sample 5 (tactic 1), the soft connection helps the external walls to shape a variety of design forms having projections or recesses. In tactic 4, extendable unit, in the type of extension in a defined zone, it is considered a particular zone for future expansion. The external edge that can allow expansion in this zone may have the soft connection abilities ${ }^{6}$.

In sample 27, 'Affordable Rural Housing' in Britain, the designer provides soft connections between spaces in the form of portable walls. This makes the ability to adapt the house to new functional changes (Figure 1). In traditional Persian houses, embedding soft connections between spaces in the form of portable thresholds has an important role in organizing necessary functional changes (Figure 2). Soft connections in the form of defined articulations have also played an important role in traditional Persian house organization. The main entrance space and its corridors are an adjustable joint between the house internal areas and the external zone. Considering the internal spaces organization, Sofeh ${ }^{7}$ or Bahar-khab ${ }^{8}$ is the joint between main spaces such as Panj-dari ${ }^{9}$ or Talar $^{10}$ with the courtyard. The spaces called Mard-gards ${ }^{11}$ are the joint between rooms and courtyard. In other parts, a variety of minor

${ }^{4}$ For example, cf. sample 9. In this sample, flexibility is considered via merging or splitting prefabricated modules and is provided through adjustable connections.

5 For example, cf. sample 22. In this sample, flexibility is considered via merging or splitting adjacent units and is provided through adjustable connections.

6 For example, cf. sample 18 in tactic 4 . In this sample, flexibility is considered via possibility to develop in the designed balconies. Such development is provided through embedding adjustable connections in the edge between closed space and balconies.

7 A raised area beside one of the sides of the courtyard usually used for sitting.

8 A kind of open space which was used for sleeping at night in warm seasons. It was a joint between closed and open areas.

9 One of the main rooms which had an aperture with five divisions.

${ }^{10}$ Room attached to the wind tower in the southern part of the courtyard. It was a space which was open to the courtyard and at its backward, it was located the wind tower.

${ }^{11}$ The semi-open corridors that connected the open space to closed space by a swirl. 'Mard' means man and 'Gard' means swirl.

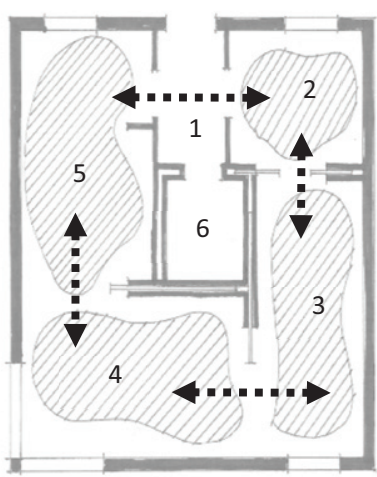

Ground Floor Plan Settlement of the components: 1 - Entrance 2 - Bedroom/study 3 - Room 4 - Living/Dining 5 - Kitchen 6 - Bath

Figure 1. The soft Connection in the form of the portable walls in sample 27, 'Affordable Rural Housing', Britain, 2000, Architect: Gokay Deveci

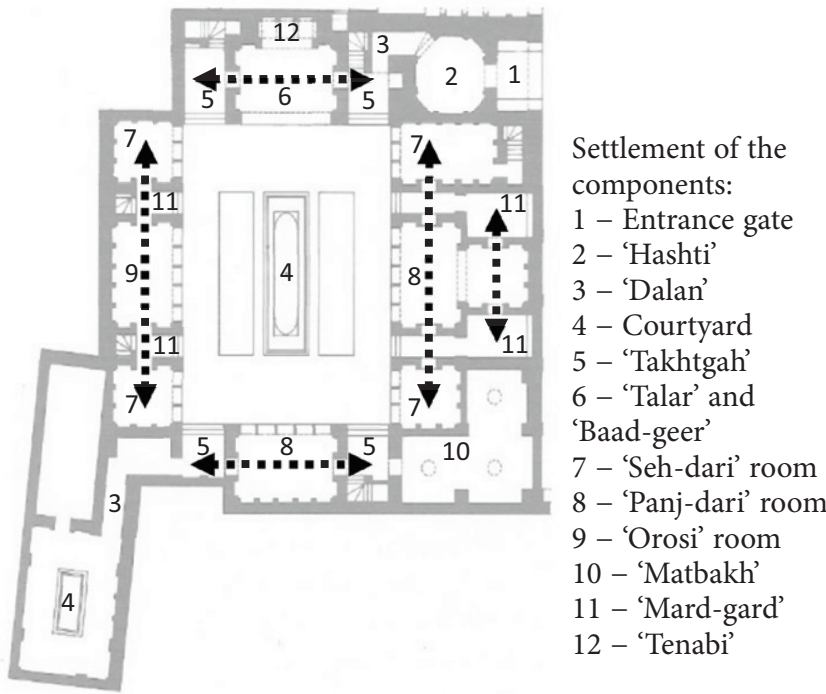

Figure 2. The soft Connection in the form of the portable thresholds in an inward-looking traditional Persian house, Sample 32

(Plan source: Ghezelbash \& Abouzia, 1985, p. 23)

spaces such as Takht-gah ${ }^{12}$ or backyards can also be studied as the joint between main spaces and are very effective in producing flexibility ${ }^{13} 14$. In the European classic houses, the traditional Japanese house and also the early American immigrant huts (samples 29, 30, 31), the soft connection can be investigated as adjustable aperture or walls between main spaces.

\subsection{Principle 2: diversity and multiplicity of spaces}

${ }^{13}$ For example, cf. sample 32, which the articulation is an important factor in organizing spaces.

${ }^{14}$ For more information about the space organization in traditional Persian house cf. Ghezelbash \& Abouzia, 1985. 
In some tactics, flexibility is embedded by considering diversity and multiplicity of spaces. Diversity and multiplicity of spaces - as a proposed principle in this part- refers to a system of spaces having a hierarchy of large scale to small scale places. This system can bear physical and functional changes better than a mono-scale system of spaces.

The small-scale spaces usually occur organically around big scale spaces or in the boundary or joint of two main space. Alexander declares that 'in general, in any system, where one center forms, as structure-preserving transformation occur, other smaller centers will then emerge ... gradually it will occur around every center' (Alexander, 2002b, p. 67). These new centers provide beautifully articulated intermediate levels of scale (Alexander, 2002b, p. 77).

Variety of different activities in a building is necessary. It results in the variety of different rooms. 'In house with a large room, and smaller rooms, the social atmosphere and the range of possibilities for life which the building provides are intensified. Even a tiny house in which there is one dramatically large room, two small rooms, and two tiny alcoves, will work very much better than one in which

Table 3. Emerging the diversity and multiplicity of spaces in the traditional and modern geometric patterns

1- Traditional geometric pattern
A hierarchical geometric
pattern that emerges an
ordered and legible context
for the diversity and
multiplicity of spaces

Examples:

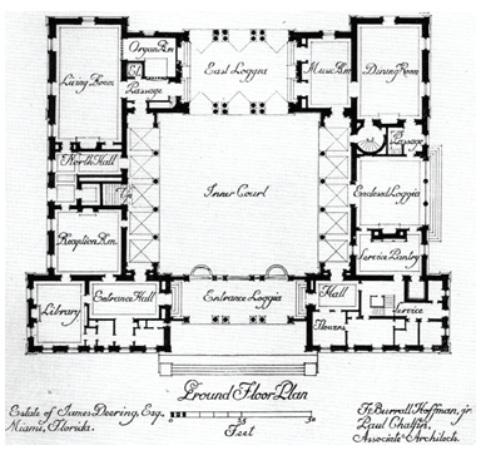

The formation of the diversity and multiplicity of spaces around the main yard in A Classical Italian House

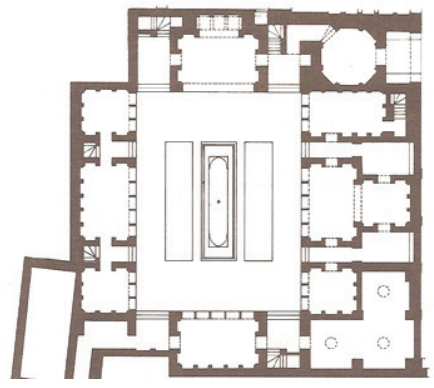

The formation of the diversity and multiplicity of spaces around the main yard in an inward-looking traditional Persian House, Sample 28

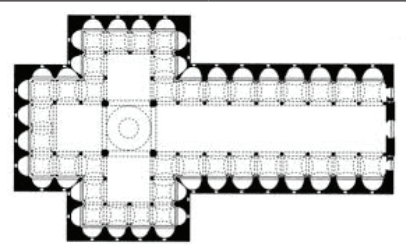

The formation of small-scale spaces around the main space in San Spirito Classical Church
Examples:

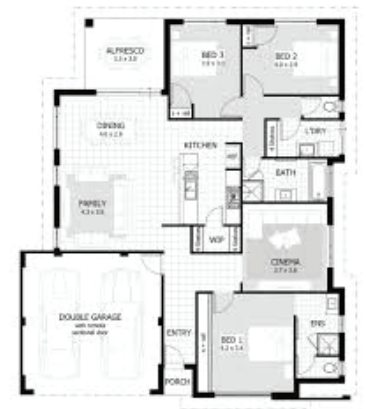

The formation of a free pattern of diversity and multiplicity of spaces in a modern residential apartment

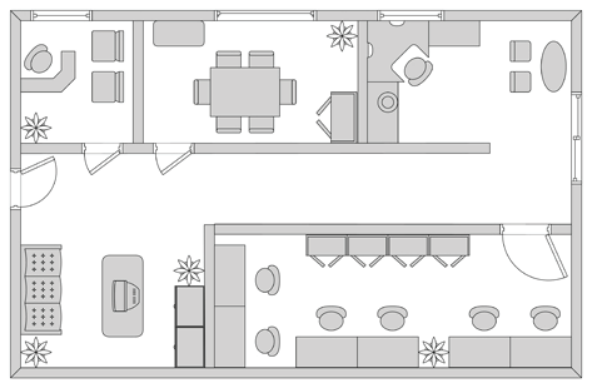

The formation of a free pattern of diversity and multiplicity of spaces in a modern office plan 
there are four equal-sized rooms. In all these examples the smaller spaces somehow bolster the life of the larger spaces; and the larger ones bolster the life of smaller ones. Thus, in these examples, levels of scale among functional centers affect the practical behavior of the building, and make it more capable of supporting life' (Alexander, 2002b, p. 150). In another example, Alexander et al. believe that 'the largest gathering places with the highest ceiling are in the middle because they are the social centers of activities; smaller groups of people, individual room, and alcoves fall naturally around the edges' (Alexander, Ishikawa, \& Silverstein, 1977, p. 567). These small-scale spaces usually accommodate diversity and multiplicity of functions and increase flexibility. In other words, such places can better respond to the functional changes. Bentley et al. (1985) believe that to increase flexibility, 'the edge between buildings and public space must be designed to enable a range of indoor private activities to co-exist in close physical proximity with a range of outdoor public activities' (Bentley et al., 1985, p. 69). In the design of public outdoor spaces, they believe that in the space edges, diversity and multiplicity of small subsidiary activities takes place.

These small scaled areas are widely used. Bentley et.al. declare that people mostly prefer the edge spaces for their activities (Bentley et al., 1985, p. 59). Paumier declares that boundaries around the main functions may be defined as multifunctional overlapping areas, suitable for people to gather for different intentions at different hours. This will also lead to increasing the vitality of the main functions (Paumier, 2004). Such functional overlapping areas can define edges between main functions and emerge diversity and multiplicity of activities leading to more flexibility. In Ellin's interpretation, 'the edge is where adaptation and change occur' (Ellin, 2006, p. 82).

In the traditional architecture, it can be considered that the small scale spaces are usually located around large-scale spaces. This system of layout presents a clear geometry that emerges an obvious hierarchy of large scale to small scale spaces. Emerging complexity of geometries in contemporary architecture, such hierarchy is not so clear (Table 3). Alexander believes that 'in the contemporary buildings, it is often hard to create a hierarchy of centers' (Alexander, 2002a, p. 155). So it can be declared that the diversity of scales (minor scale to large scale) in contemporary architecture is decreased in comparison to what can be seen in traditional architecture.

As it can be seen in examples, diversity and multiplicity of spaces emerges in usual designs. It seems that whatever the diversity and multiplicity of spaces increases, the flexibility increases too. In tactic 2 , using several prefabricated modules or in tactic 3 , using a number of similar spaces, flexibility is increased because of the multiplicity of spaces. The formation of the diversity and multiplicity of small-scale spaces around the main space is visible in some recent flexible designs (Figure 3).

In the inward-looking organization of the traditional Persian house, the yard has an important functional role as the central area. The formation of the diverse multi-

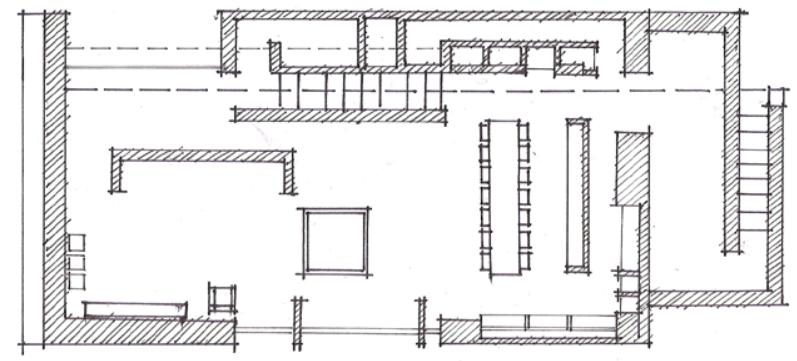

Figure 3. The formation of the diversity and multiplicity of small-scale spaces around the main space to accommodate subsidiary functions, 'La House', Brazil, 2009, Studio Guilherme Torres

ple rooms around the central yard can provide a range of adaptability for future changes (Figure 2). Minor-scaled zones around the main areas can also increase functional adaptability in this house. The formation of small-spaces such as 'Tenabi'15 at the rear part of 'Talar', 'Pastoo'16 at the rear part of the main rooms (rooms such as Se-dari ${ }^{17}$ or Panj-dari) or even 'Taghche's ${ }^{18}$ and 'Raf's ${ }^{19}$ as very small scale areas around the rooms can emerge this principle.

\subsection{Principle 3: multifunctional space}

In some tactics, the flexibility occurred via providing multifunctional space. Multifunctional space has the ability to embed diversity of activities. The suitable variety of functions for a specific space should be defined according to the space meaning and essence ${ }^{20}$. In such a process, it can be considered that the multiple activities are compatible because they are derived from common essence and meaning. Norberg-Schulz belief when he declares that the place opens a territory that gathers things that belong to each other (Norberg- Schulz, 1988) may implies such compatibility. It can also be considered that in this process, these multiple activities have mutual interaction. Hence, while speaking of multifunctional space as the third principle of flexibility, the diversity and multiplicity of activities should be defined in such compatible and interactive characteristics. This will lead to a sense of liveliness and richness in space.

${ }^{15}$ A particular room at the rear side of the 'Talar'. It usually gets light by the roof.

${ }^{16}$ Storage room at the rear part of the inward-looking traditional Persian house main rooms.

${ }^{17}$ The secondary room (in comparison to Panj-dari) which has an aperture with three divisions.

${ }^{18} \mathrm{Niches}$ at the lower level of the walls of the inward-looking traditional Persian house, at the reach of users.

${ }^{19}$ Niches at the higher level of the walls of the inward-looking traditional Persian house, higher than the reach of users.

${ }^{20}$ Robert Venturi emphasized on the meaning when he discusses 'double functioning' element. He proposes the concept of 'both-and' and believes that 'both-and' emphasizes double meaning over double functions" (Jencks \& Kropt, 2007, p. 42). 
It can be usually seen in multifunctional places that a range of marginal activities occur beside or around the main activity. As defined in the previous part, the marginal activities can imply the small centers emerging around the center as the main activity. Jane Jacobs believes that the multiple and diverse functions grow in response to giving service to an existing activity and in order to give service to the people that the main function attracts them. She believes that diversity can be inefficient unless it is dependent to a main function. In such condition, it can produce liveliness (Jacobs, 1992). Bentley et al. (1985) emphasize on paying attention to place margins while designing the public spaces. They believe that it is here that most activities take place' (Bentley et al., 1985, p. 59).

In some other multifunctional spaces, the main activity is not defined. In such cases, the multifunctional space may be produced by the interaction of some equal functions. Bentley et al. (1985) believe that the principle for supporting robustness is to design settings which, as far as possible, enable a variety of activities to co-exist in the public realm without inhibiting each other' (Bentley et al., 1985, p. 60). They declare that 'designers should get the most variety they can' (Bentley et al., 1985, p. 28).

Differences in the formation of multifunctional spaces are shown in Table 4.

As it can be seen in examples, multifunctional spaces may emerge in usual designs. It seems that if the required margin for subsidiary activities is provided, the flexibility increases.

Considering flexible samples, the diversity of activities in the margins occurs via the portable, retractable or foldable furniture. In some of the flexibility tactics such as tactic 8 , retractable furniture in the multifunctional space,

Table 4. Differences in the formation of multifunctional spaces

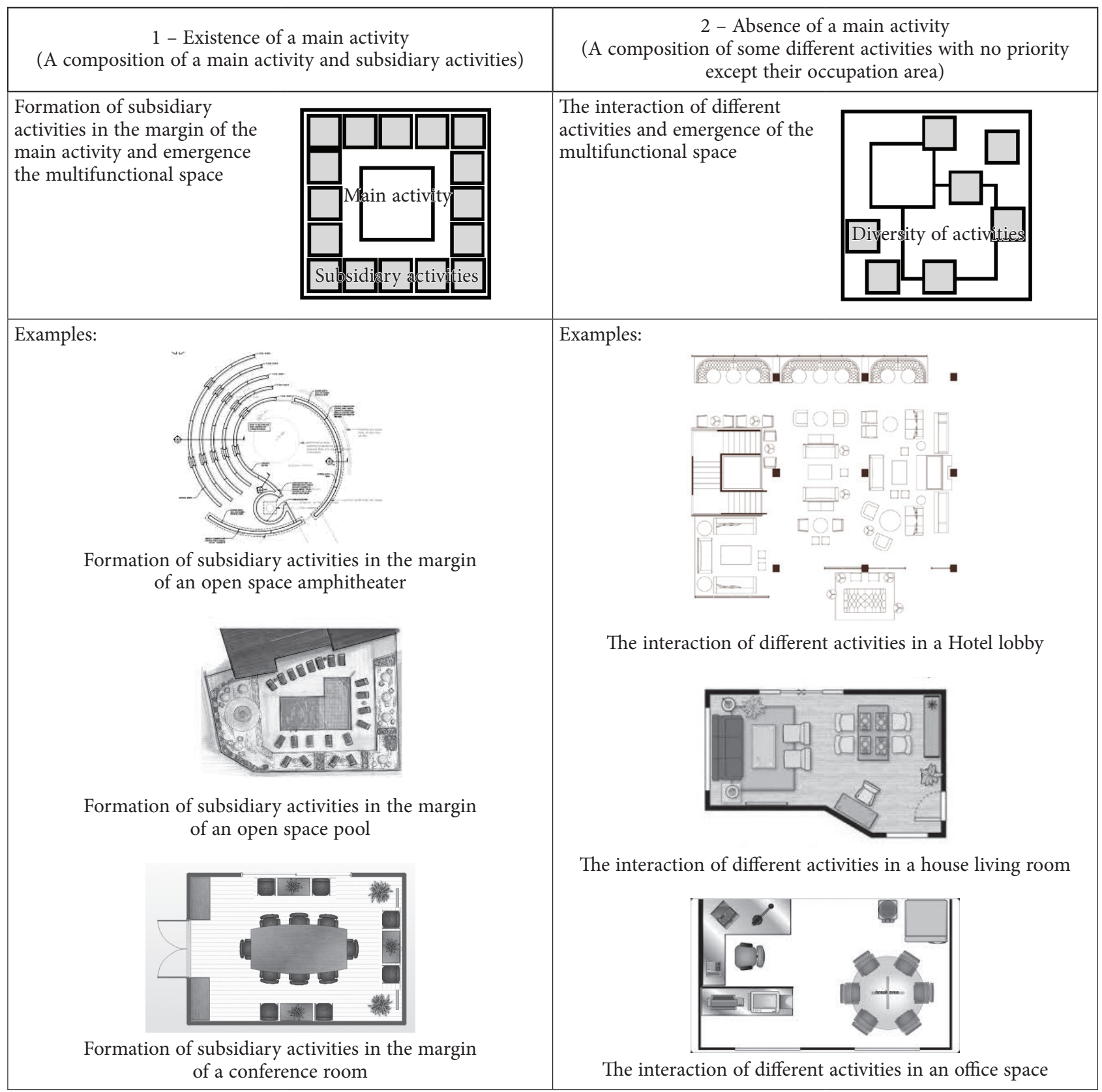




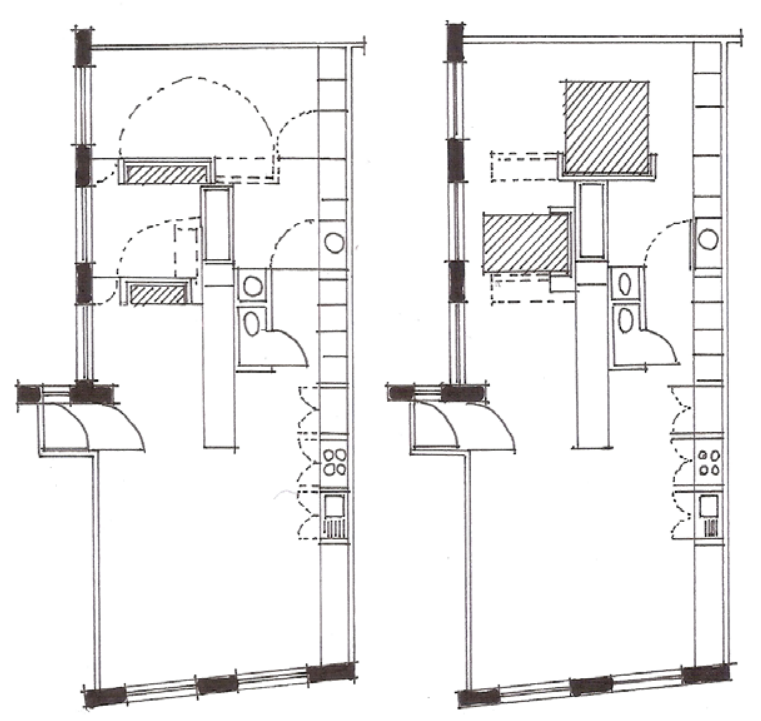

Figure 4. Embedding beds and other furniture in the walls as the edges of the rooms to allow multiple activities occur in the center, sample 33, 'The Transformable Apartment', Britain, 1996, Mark Guard Architects

retractable and foldable furniture is located at the space edges that has the ability to be moved, contracted or expanded (Figure 4).

In the traditional spaces, the space design basis is not functional. So it can response to a diversity of functions according to different situations. In traditional Persian house, the spaces can accept different activities at different times of a day, different seasons and over passing years (Ghezelbash \& Abouzia, 1985, p. 25). In this architecture, the activities usually occur on the ground level and usually are not dependent to any special furniture. So the number of existing furniture is limited and are usually simple and light. This caused the furniture to be moved or retracted very easily. Besides, the free space of the rooms provides suitable ground to accept multiple activities.

\section{Conclusions}

As mentioned before, the main objective of this paper is extracting conceptual roots and principles of flexibility and proposing a comprehensive model in this regard. The paper discussions explore the identified methods, categorized the tactics and presented an analytical ground. In this regard, the paper's analysis, supported by researchers interpretations and case studies, leads to the three main principles relating flexibility which are 'soft connection', 'diversity and multiplicity of spaces' and 'multifunctional space. The study of flexible samples shows the below relationships between principles and tactics:

- The first principle, 'soft connection', has the properties that are applied in tactic 1, 2, 4, 5, 6, 7, as well as traditional samples.

- The second principle, 'diversity and multiplicity of spaces', has the properties that are applied in tactics 2,3 , as well as traditional samples.

- The third principle, 'multifunctional space', has the properties that are applied in tactic 8 , as well as traditional samples.

In this regard, the relationships extracted between principles and tactics can be introduced in the 'convergent model of flexibility' which is shown in Figure 5. The model consists of 3 layers. The outer layer includes the tactics related to 'multifunctional space' properties. The intermediate layer includes the tactics related to the diversity and multiplicity of spaces' properties. The inner layer includes the tactics related to the 'soft connection' properties.

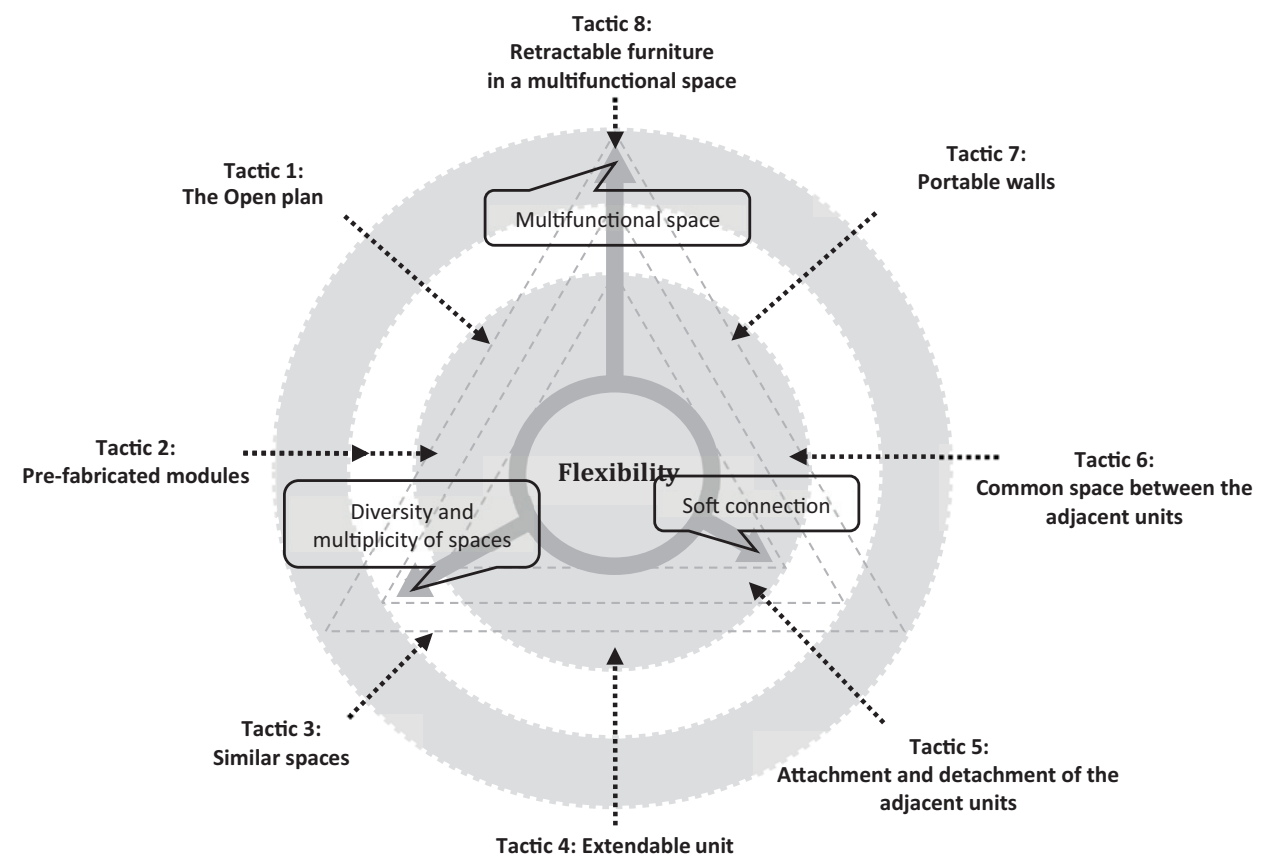

Figure 5. The convergent model of the principles and tactics of flexibility 
Among these three characteristics, the soft connections only emerge in flexible structures. But two other characteristics, as are introduced in pre-mentioned sections, may be seen in other structures.

At the same time, flexibility can be dependent not only upon types of connections but also upon the types of spaces (multifunctional spaces) and the type of their composition (diversity and multiplicity of spaces). So these characteristics have the different position in an architectural structure. These different positions are shown in Table 5.

Accordingly, it can be said that these characteristics are complementary and simultaneous realization of the three principles can lead to a comprehensive approach to flexibility. The traditional samples benefit the three principles, but the modern approaches usually concentrate on one of the principles.

In this regard, this paper proposes a rule for flexibility as: 'soft connections' between 'diversity and multiplicity of multifunctional spaces'.

This rule can be presented more concisely while these attentions are paid:

First, diversity and multiplicity of spaces can be implied in the plural 's' of the word 'spaces'.

Secondly, it can also be said that the multifunctionality was a natural characteristic of the space before the modern functionalist manifestos. So it can be implied in the essence of space naturally.

Accordingly, the concise rule of flexibility in architecture can be defined as 'soft connections between spaces'.

What this rule simply implies is:

First, as far as possible, it is embedded soft connection (controllable joint) between different spaces.

Secondly, as far as possible, it is embedded diversity and multiplicity of different scale (minor-scale to largescale) of spaces.

Thirdly, as far as possible, it is embedded adequate margin around main functions which can lead to the emergence of multifunctional space.

So, although the rule seems to be very simple, the paper argumentations show that paying attention to what it implies, can produce much more flexible spaces than what is created generally. At the same time, as it can be seen in the flexible samples, new creative ideas along supported by new emerging technologies can enrich these simple solutions extensively.

Table 5. Position of influence of flexibility characteristics

\begin{tabular}{|l|c|c|c|}
\hline \multirow{2}{*}{\begin{tabular}{c}
\multirow{2}{*}{$\begin{array}{c}\text { Flexibility } \\
\text { characteristics }\end{array}$} \\
\cline { 2 - 4 }
\end{tabular}} & \multicolumn{3}{|c|}{$\begin{array}{c}\text { Positions of influence of } \\
\text { flexibility characteristics }\end{array}$} \\
\cline { 2 - 4 } & Connections & Spaces & $\begin{array}{c}\text { Composition } \\
\text { of Spaces }\end{array}$ \\
\hline 'Soft connection' & $\checkmark$ & $\checkmark$ & \\
\hline $\begin{array}{l}\text { 'Multifunctional } \\
\text { spaces' }\end{array}$ & & & $\checkmark$ \\
\hline $\begin{array}{l}\text { 'Diversity and } \\
\text { multiplicity of spaces' }\end{array}$ & & & \\
\hline
\end{tabular}

The research results can be applied for providing a theoretical basis for flexibility. It can also be used for flexibility tactics analysis and evaluation. The research results can be extended discussing the principles in different architectural functions. The principles may have different executive characteristics or definitions in different buildings such as residential, educational, cultural, religious, commercial and office buildings.

\section{Acknowlegements}

I would like to show my gratitude to Dr. Alireza Einifar and Seyed Hossein Asadi Khonsari for their comments on an earlier version of the manuscript. Their ideas help greatly to improve the research structure.

\section{References}

Alexander, C. (2002a). The nature of order - book one. Berkeley: The Center for Environmental Structure.

Alexander, C. (2002b). The nature of order - book two. Berkeley: The Center for Environmental Structure.

Alexander, C., Ishikawa S., \& Silverstein, M. (1977). A pattern language. New York: Oxford University Press.

Bentley, I., Alcock, A., Murrain, P., McGlynn, S., \& Smith, G. (1985). Responsive environments. London: The Architectural Press.

Capon, D. S. (1999). Architectural theory - volume one. U.K.: John Wiley.

Crinson, M. (2012). Stirling and Gowan: architecture from austerity to affluence. Paul Mellon Centre BA.

Einifar, A. (2003). A model to analyze residential spaces: based on flexible criteria of traditional housing. Journal of Fine Arts, 13, 64-77.

Ellin, N. (2006). Integral urbanism. New York: Routledge.

Gao, A. (2012). 100 home design principles. London: Design Media Publishing Limited.

Gardiner, S. (2002). The house: its origins and evolution. U.K.: Ivan R. Dee.

Ghezelbash, M., \& Abouzia, F. (1985). Alphabets of Yazd traditional house. Tehran: Program and Budjet Organization.

Grütter, J. K. (1987). Ästhetik der Architektur: Grundlagen der Architektur-Wahrnehmung. Stuttgart: Kohlhammer.

Jacobs, J. (1992). The death and life of great American Cities. Reissue edition: Vintage.

Jencks, C. (1987). What is post-modernism. New York: Second printing, Academy Editions.

Jencks, C., \& Kropt, K. (2007). Theories and manifestoes of contemporary architecture. London: Wiley-Academy.

Kronenburg, R. (2002). Houses in motion. London: Wiley Academy.

Kronenburg, R. (2007). Flexible, architecture that responds to change. London: Laurence King Publishing.

Lynch, K. (1984). Good city form. USA: The MIT Press.

Marks, R. W. (1960). The Dymaxion world of Buckminister Fuller. New York: Southern Illinois University Press.

Norberg-Schulz, C. (1988). Architecture: meaning and place. New York: Rizzoli.

Paumier, C. (2004). Creating a vibrant city center. Washington: The Urban Land Institute.

Schneider, T., \& Till, J. (2007). Flexible housing. Oxford: Architectural Press.

Schneider, T., \& Till, J. (2005). Flexible housing: opportunities and limits. Architectural Research Quartely, 9(2), 157-166. https://doi.org/10.1017/S1359135505000199

Venturi, R. (1966). Complexity and contradiction in architecture. New York: The Museum of Modern Art. 